\title{
¡Cuidado! Jóvenes, fútbol y aguante en la vía: la pasión del fútbol en las carreteras de Colombia*
}

\author{
Alejandro Villanueva* \\ Rafael Mendivelso ${ }^{* * *}$ \\ Omar Rivera ${ }^{* * *}$
}

\begin{abstract}
Este proyecto se desarrolló en el marco de un convenio interinstitucional entre la Universidad de Cundinamarca (Facultad de Educación, programa de Licenciatura en Ciencias Sociales sede Fusagasugá) y la Universidad Nacional de Colombia sede Bogotá, (Departamento de Sociología y Maestría en Sociología).

** Licenciado en Ciencias Sociales y magíster en Educación por la Universidad Pedagógica Nacional (Colombia). También, es magíster en Sociología y doctor en Ciencias del Deporte y Educación Deportiva por la Universidad Nacional de Colombia. Actualmente es docente e investigador de la Facultad de Educación Física en la Universidad Pedagógica Nacional (Colombia). https://orcid.org/00000002-6437-7945. Correo electrónico: avillanuevabustos@gmail.com

*** Licenciado en Sociología, y candidato a magíster en Estudios Sociales de la Ciencia en la Universidad Nacional de Colombia. Integrante del Comité del Grupo de Estudios Sociales del Deporte (GESDE). https://orcid.org/0000-0001-5699-5041

${ }^{* * * * *}$ Licenciado en Ciencias Sociales por la Universidad Pedagógica Nacional (Colombia). Investigador y consultor en Educación y Estudios Sociales. Actualmente es docente universitario y coordinador del Centro Regional Orlando Fals Borda de la Universidad de Cundinamarca (Colombia). https://orcid. org/0000-0003-4785-396X. Correo electrónico: ofrivera@ucundinamarca.edu.co
\end{abstract}

Fecha de recepción: 8/05/2020. Fecha de aceptación: 12/11/2020. 
¡Cuidado! Jóvenes, fútbol y aguante en la vía: la pasión del fútbol en las carreteras de Colombia

\title{
RESUMEN
}

Este documento tiene como objetivo dar a conocer los avances en los resultados del proyecto de investigación «Rutas de expresiones juveniles en organizaciones barristas, un recorrido entre Bogotá, Soacha, Fusagasugá y Girardot. Periodo 2018-2019». Esta iniciativa de investigación expone como objetivo general desentrañar, analizar y comprender las formas y dinámicas de vida y subjetividades de integrantes de las mal llamadas barras bravas de fútbol. La pesquisa ofrece como aporte y novedad deslocalizar los escenarios o espacios predilectos de las investigaciones realizadas en las líneas de violencia y fútbol o violencia y deporte.

En esta investigación se presenta una relación estrecha entre la concepción del territorio y la territorialidad, a partir del aguante, que se alimenta del vértigo y la velocidad que producen en el hincha que viaja, a partir de los recuerdos, las experiencias y los relatos que aumentan su afición y amor por el equipo, apropiando territorios en la carretera y estrategias para sobrevivir y convertirse en guerreados de la hinchada.

Palabras clave: guerriados, caminantes, fútbol, conflicto, pasión.

\section{Watch out! Young people, soccer and endurance on the road: the passion of soccer on the roads of Colombia}

\begin{abstract}
This document aims to publicize the progress in the results of the research project «Routes of youth expressions in barristas organizations, a journey between Bogotá, Soacha, Fusagasugá and Girardot. Period 2018-2019». This research initiative presents as a general objective to unravel, analyze and understand the ways and dynamics of life and subjectivities of members of the so-called white football bars. The research offers as a contribution and novelty the relocation of the scenarios or favorite spaces of the research carried out in the lines of violence and football or violence and sport.

This research presents a close relationship between the conception of the territory and the territoriality, from the stamina, which feeds on the vertigo and the speed they produce in the traveling fan, from the memories, experiences and stories that increase their love for the team, appropriating territories on the road and strategies to survive and become the warring of the swollen. Road warriors, walkers, football, conflict and passion.
\end{abstract}

Keywords: warriors, walkers, soccer, conflict and passion. 


\section{A manera de calentamiento}

Dar cuenta en la actualidad de un fenómeno como el barrismo desde una perspectiva académica e investigativa en Colombia supone hacer una revisión general de los diversos y ya números trabajos como las tesis de grado en los niveles de pregrado, maestría y doctorado. Estos trabajos de carácter académico se han producido en cantidades importantes en especial durante los últimos quince años, abarcando desde el año 2004 hasta 2019, de tal manera que se han abordado diferentes temáticas o intereses como procesos identitarios y de reconocimiento de las barras futboleras, sus prácticas sociales, imaginarios sociales, formas de violencia, su participación y accionar política, etc. Asimismo, estas temáticas han sido encaradas desde distintos enfoques de las ciencias humanas y sociales como la sociología, antropología, historia, geografía, trabajo social, psicología y educación.

Asimismo, al observar abordajes desde otras áreas disciplinares se reconoce el importante cúmulo de tesis desarrolladas en los programas de Comunicación Social y Periodismo, así como los trabajos realizados en marco de la formulación y evaluación de políticas públicas en el fútbol y reflexiones de corte legislativo por politólogos, abogados y administradores deportivos. De tal manera que casi dos décadas después del surgimiento de un fenómeno social tan interesante y complejo como lo es el barrismo, ya es posible contar con un importante acervo académico e investigativo presente en bibliotecas, bases de datos y repositorios digitales de diferentes universidades e instituciones del país.

No obstante, es fundamental avanzar hacia el siguiente nivel, y este está significativamente relacionado con la planeación, implementación y desarrollo de múltiples y variados procesos, proyectos e intervenciones con enfoques territoriales, análisis de coyuntura y caracterizaciones de grupos sociales en los contextos en los cuales se hacen visibles y notables las relaciones y acciones de los integrantes de las distintas barras futboleras en todo el territorio colombiano. Al ir desarrollando estas reflexiones, se avanzará en la aplicación de la consigna: conocer a fondo para interpretar las diversas formas de relacionamiento social de estos grupos.

En este orden de ideas, surge la necesidad de pensar, reflexionar y comprender lo que ha venido sucediendo con varios grupos de hinchas de los distintos equipos del fútbol colombiano, y más teniendo presente, que en los últimos años se han tomado las carreteras que comunican a una parte importante del territorio colombiano. El objetivo primordial de viajar es alentar a su equipo en territorios no locales. Esta travesía de movilidad que es asumida por algunos hinchas de forma organizada y desorganizada se realiza así se presenten condiciones adversas como contar con escasos recursos económicos y con la tensión de entablar en el trayecto confrontación violenta con miembros de otras organizaciones o grupos barristas. En estos recorridos también se producen prácticas recursivas y particulares a la hora 
de movilizarse por carreteras y ciudades. Una práctica llamativa y recurrente de estos barristas, es la de esperar en puntos estratégicos del recorrido la oportunidad de poder subir a tractomulas o camiones de carga con el propósito de ser movilizados al lugar de destino de forma gratuita y rápida.

Ahora, partiendo de reconocer que los estudios sobre fútbol, violencia y barrismo se consolidaron como una línea de investigación en la academia colombiana, y que se ha generado un gran número de producciones académicas e investigativas frente al tema. También se debe reconocer que aún faltan abordajes frente al fenómeno del barrismo que sirvan como instrumentos analíticos, conceptuales y metodológicos para el reconocimiento, comprensión y transformación de dinámicas socioculturales que permitan una mejor convivencia del fútbol en todas sus expresiones.

Conscientes que algunas dinámicas socioculturales que se producen en el barrismo no han sido abordadas de manera suficientemente, la presente investigación partió por preguntarse por la movilidad, el territorio y las hinchadas de futbol. Asimismo, la investigación se planteó por la necesidad de visibilizar las prácticas no sólo de las hinchadas que presentan un tipo organización y acciones colectivas, también por aquellos barristas que son considerados los más excluidos entre los excluidos, nos referimos a las y los jóvenes que sin presupuesto suficiente para viajar, comer y entrar a los estadios deciden caminar por alentar, fortalecer y exteriorizar su pasión futbolera. A estos sujetos se les ha llamado: caminantes, guerriados, piratas o zapateros (Ver foto 1).

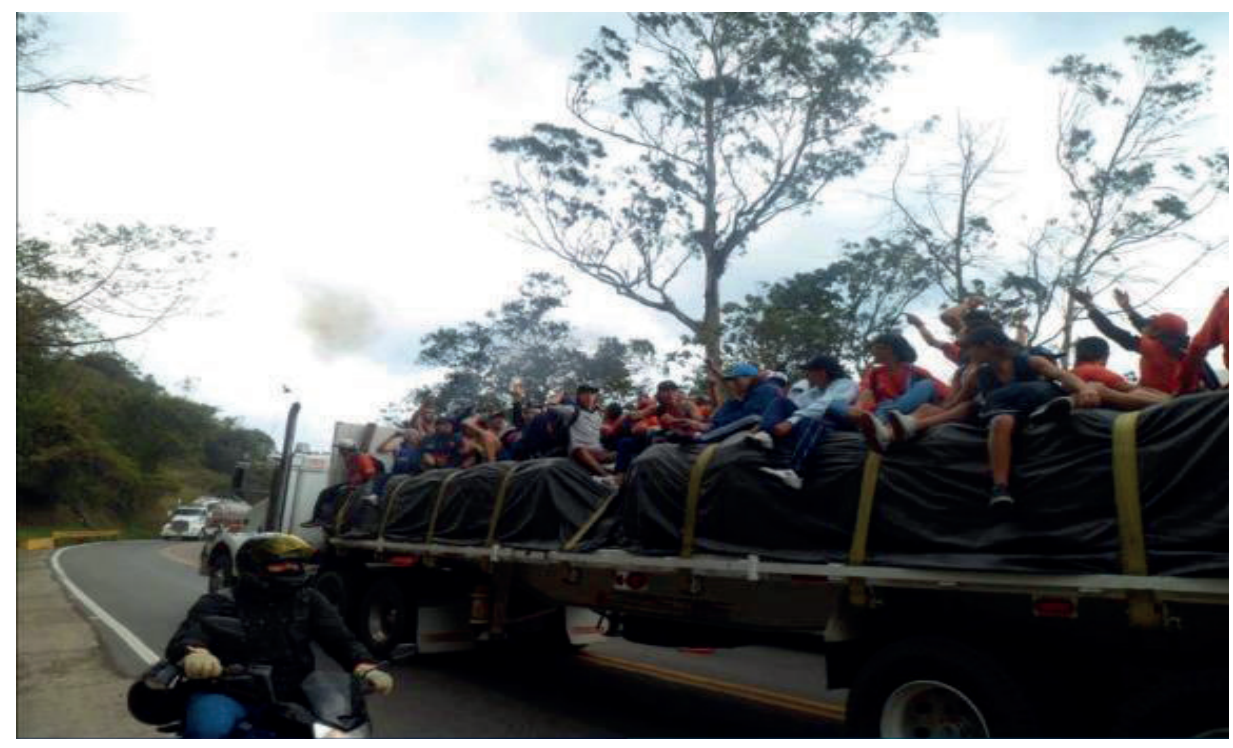

Foto 1. Hinchas del América de Cali, vía Bogotá-Armenia en el Boquerón de Ibagué. Tomada por Sergio Andrés Caro (2019). 


\section{INTRODUCCIÓN}

El proyecto permitió reconocer la configuración del territorio (Montañés, 2004) y la capacidad del viaje como experiencias del hincha o la hinchada por algunas regiones del país, donde se configuran relaciones de intercambio e interacción con otras organizaciones barristas y actores ajenos a las dinámicas de las hinchadas futboleras. La pesquisa se focaliza en territorios de los municipios del Departamento de Cundinamarca que se configuran en nodos de las rutas, tanto de ida como de regreso, de hinchas de diferentes equipos de la liga colombiana, que recorren el país acompańando a sus equipos.

En este proceso de intercambio se evidencian diferentes expresiones en la apropiación del territorio (territorialización, Montañez ); expresiones de conflicto por las confrontaciones entre hinchas de equipos contrarios; expresiones de solidaridad en los procesos de asimilación de organizaciones barristas que pertenecen a los municipios que conforman este recorrido, logrando acompańamiento en el viaje como lugares de alojamiento y alimentación en el proceso organizativo del colectivo barrista; expresiones simbólicas en puntos específicos del trayecto vial y al interior de los municipios.

Otras expresiones que se analizaron fueron las interacciones que se generan con actores que son independientes a las actividades que giran alrededor del fútbol profesional colombiano. Entre los actores externos a la hinchada se pueden mencionar los vendedores de carretera, tanto informales como formales, las autoridades de tránsito, conductores, habitantes de municipios pertenecientes a los departamentos de Cundinamarca y Tolima.

Durante el desarrollo del proyecto evidenció someramente la relación entre la ruralidad como escenario de transformación permanente en relación con las expresiones urbanas que parecen llegar a municipios e impactar socialmente a los territorios, al encontrarse en una de las rutas de acceso a la ciudad capital, y también como puertas de intercambio con diferentes regiones del país que recorren y encuentran diferentes formas de reconocer al otro, y las formas de expresarlo en el campo simbólico y en agresiones violentas por pertenecer a un equipo de fútbol diferente.

El objetivo general que guío la investigación fue reconocer expresiones juveniles, recorridos y experiencias de viaje de organizaciones de barras futboleras que transitan entre Bogotá, Soacha, Fusagasugá y Girardot, para asistir a los distintos partidos del fútbol profesional colombiano en el periodo 2018-2019.

Como objetivos específicos se buscó: 1) Localizar los trayectos viales que toman las barras futboleras para su movilidad entre Bogotá y los municipios de Soacha, Fusagasugá y Girardot. 2) Caracterizar y comprender expresiones juveniles que se generan en los recorridos viales de las barras futboleras entre Bogotá y los municipios 
de Soacha, Fusagasugá y Girardot. 3) Reconstruir narrativas de viajes y experiencias de hinchas y su relación con los territorios recorridos.

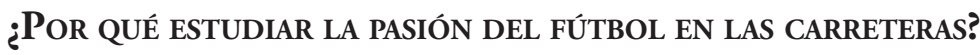

Reconocer una de las principales rutas viales que toman las organizaciones barristas permite entender a este grupo poblacional más allá de los estigmas sociales que los han etiquetado como una "población peligrosa", desde una óptica normativa y reglamentaria impuesta por la población adulta y reproducida por actores institucionales del Estado como: la fuerza pública, actores mediáticos como los medios de comunicación.

El fenómeno del barrismo en el contexto colombiano y latinoamericano ha dejado de ser un escenario de poca importancia para actores estatales y académicos (Quitian, 2012; Alabarces, 2012). Ahora, tanto el campo académico como agendas políticas han asumido la importancia de estudiar, comprender y atender las diferentes realidades, dinámicas y expresiones que este grupo de sujetos producen y materializan en sus interacciones con el territorio y demás sujetos externos a las dinámicas del barrismo.

Desde el estamento académico colombiano podemos expresar que la temática hegemónica en el escenario de los estudios sociales del deporte, es el fenómeno del barrismo. El trabajo realizado por Villanueva y Mendivelso (2018) en la búsqueda, compilación y exposición de los diferentes productos académicos que han abordado directa y tangencialmente el fenómeno del barrismo, presenta como dato estadístico relevante que durante los últimos 15 ańos se han producido más de 140 productos de investigación. Esta producción científica en su radiografía expresa como principal reflexión que el barrismo ha sido un interés privilegiado en la agenda de los estudios sociales del deporte en el contexto colombianos, y dicha producción se ha abordado de manera inter y transdisciplinar, presentando una heterogeneidad de objetivos, abordajes metodológicos y resultados de investigación.

Desde una respuesta estatal, se pueden mencionar las diferentes preocupaciones que han manifestado diferentes actores políticos frente a las problemáticas y consecuencias que han producido las expresiones violentas por parte de los integrantes de las organizaciones barristas, dentro y fuera de los estadios de fútbol. Un antecedente de políticas públicas y normatividades creadas para abordar la problemática de la reproducción de hechos violentos en relación al espectáculo futbolero. Iniciativas como el Programa Goles en Paz, el cual se creó con iniciativa de la alcaldía de Bogotá en el año 2004 por medio del decreto 163, y cuyos objetivos partían de configurar una alternativa institucional para controlar los brotes de violencia generados por integrantes de organizaciones barristas. 
Una potencialidad del proyecto Ruta de expresiones juveniles en organizaciones barristas, un recorrido entre Bogotá, Soacha, Fusagasugá y Girardot. Periodo 20182019, fue el abordaje territorial. Partiendo de los diferentes estudios e investigaciones del barrismo en Colombia, se generaron reflexiones desde una ruta de movilidad barrista, lo que conlleva a analizar diferentes territorios teniendo presente las particularidades sociales de cada uno.

Por último, comprender la configuración de una subjetividad barrista, relaciones de solidaridad, procesos identitarios al interior de estas organizaciones y las formas de interacción con actores externos. Esto será otro eje principal de la investigación, donde se espera ir más allá de los hechos referidos a la violencia, y mostrar actividades internas y no violentas de estos grupos de hinchadas.

Un primer reconocimiento de los actores que integran las organizaciones barristas e hinchas guerriados o caminantes, permitió encontrar juventudes tempranas conviviendo con las siguientes características: primero, en condición de «alta vulnerabilidad» (De La Lama, 2011); segundo, agrupados en organizaciones des-jerarquizadas con una lógica más "celular", es decir, respondiendo a pequeños grupos con jerarquía interna, que actúan autónomamente y ocasionalmente articulan con otros sujetos; tercero, su actuar atiende a dinámicas del control territorial, semejantes a una pandilla y expresando referentes netamente emotivos, simbólicos e identitarios.

\section{ABORDAJES ACADÉMICOS SOBRE BARRISMO}

Como se mencionó anteriormente el fenómeno del barrismo ha acaparado la atención de académicos e investigadores de las ciencias humanas y sociales. El sociólogo David Quitian, en un ejercicio de caracterizar el surgimiento del campo de los estudios sociales del deporte en Colombia, concluye que al realizar una panorámica a la bibliografía se pueden visualizar temáticas o relaciones al interior del campo del deporte, a saber: nación y deporte, identidad, narrativas, historia del deporte, violencia y barras de fútbol (Quitian, 2012).

En clave colombiana, al interior del campo de los estudios sociales del deporte —aún en consolidación-, el fenómeno del barrismo genera un gran aporte en materia de producción académica. Y al observar ¿cómo? y ¿̇de qué manera? se han producido las diferentes investigaciones, podemos dilucidar que los estudios sobre el barrismo presentan un carácter transdisciplinar, con diferentes estilos de producciones (monografías, tesis de maestría, artículos científicos, ponencias en eventos académicos nacionales e internacionales, etc.); y con diferentes abordajes y resultados (Villanueva y Mendivelso, 2018). 
A continuación, se presenta un bosquejo de estado del arte del barrismo en conexión con los objetivos del proyecto de investigación, lo cual permitirá exponer e interpretar diferentes violencias a las que se encuentran expuestos estos jóvenes barristas y así, visualizar condiciones sociales, económicas y subjetivas, con el fin de comprender el porqué de sus afiliaciones a estos grupos. Complementariamente, en la búsqueda de productos académicos se seleccionaron los trabajos que buscaron en sus objetivos identificar las dinámicas, acciones, división del trabajo, roles de género y fricciones que se presentan al interior y exterior de los diferentes grupos barristas. Para la revisión bibliográfica se recurrió a una primera búsqueda por bases de datos académicas como la Journal Store, Scielo, Redalyc; y en los catálogos de revistas académicas y bibliotecas de universidades como la Universidad Nacional de Colombia, Universidad Pedagógica Nacional, Universidad de los Andes, Universidad el Externado, Universidad Santo Tomas, entre otras. A continuación, una descripción de investigaciones en torno al barrismo, la identidad y la violencia.

\section{Escenario internacional}

Ferrandiz y Feixa (2005) en su libro, Jóvenes sin tregua: culturas y políticas de la violencia, exponen una serie de estudios etnográficos cuyo objeto es comprender a los jóvenes en los contextos de violencia. Para ello, se han recopilado investigaciones de los cinco continentes, haciendo especial énfasis en América Latina. El texto consta de tres partes, en la primera, se establece una relación entre juventudviolencia-política, en donde se abordan las condiciones estructurales y de poder que se asocian en esta triada. La segunda parte, trata de indagar las culturas de la violencia entre los jóvenes que hacen parte de grupos y guetos como grupos de boxeo, hinchas de fútbol, redes sociales entre otros. Finalmente, en la tercera parte, los autores buscan construir nuevos paradigmas de interpretación social y cultural de la relación juventud-violencia, que se alejen de la perspectiva criminal o de orden.

Pegoraro (2002) en su artículo «Notas sobre los jóvenes portadores de la violencia juvenil, en el marco de las sociedades pos-industriales» aborda la violencia juvenil como fenómeno social. Analiza y describe los enormes límites de las respuestas del sistema penal actual frente a las condiciones de vulnerabilidad y riesgo en la que se encuentran los jóvenes de las sociedades pos-industriales. De igual forma, expone la situación de pobreza y exclusión a la que se ven enfrentados los jóvenes para sobrevivir en las zonas urbanas, las pocas oportunidades laborales y la escasa formación superior a la que tiene acceso. Finalmente concluye, que los jóvenes se asocian en tribus, bandas, barras y guetos sociales como respuesta a la exclusión social.

El artículo denominado "Violencia grupal juvenil: una revisión crítica» (Bárbara y otros, 2002), se aborda la relación que existe entre la violencia grupal juvenil, las 
condiciones de género, las interacciones que se desarrollan en el ámbito familiar y escolar. Además, se aproxima a otros determinantes de ciertas conductas violentas en la población joven, como la coyuntura socioeconómica, la situación de maternidad o paternidad a temprana edad que enfrenta un porcentaje de este grupo social. Concluye en la necesidad de establecer reglas y lineamientos de normalización social, que deben acompañados de condiciones sociales que aseguren su viabilidad.

Asimismo, León (2011) en su texto «Pobreza, vulnerabilidad y calidad de vida en América Latina: Retos para la bioética», expone algunos datos éticamente relevantes sobre la pobreza y la alta vulnerabilidad de la población joven de América Latina. En consecuencia, es importante señalar que conceptos como la vulnerabilidad y el homicidio son las tendencias más usadas, para comprender el fenómeno de la violencia en la juventud.

\section{Escenario nacional}

Es importante destacar que, en términos cronológicos, los estudios sociales relacionados con actores sociales como las mal llamadas «barras bravas» o «barristas» (Villanueva, 2013), completan en Colombia casi veinte años. Sin embargo, aunque rigurosas, son escasas las investigaciones donde se hace referencia a los territorios que transitan, habitan e intervienen los integrantes de los colectivos de jóvenes de las distintas barras de fútbol. Al respecto, Clavijo (2004) plantea: «Partiendo de las evidencias observadas en el trabajo de campo, y desde la noción de Campo Deportivo, se fue orientando el enfoque teórico con base en la realidad de las dinámicas de grupo, lo que finalmente condujo a destacar dos categorías básicas como lo son la Territorialidad y la Identidad».

El planteamiento anterior brinda una idea sobre la importancia de desarrollar investigaciones enfocadas en la relación fundamental entre las prácticas sociales y culturales de los barristas, sus formas de interacción social, pero sobre todo las apropiaciones simbólicas de los distintos territorios tale como: parques, plazas, carreteras, pequeños municipios y otras ciudades; dando lugar a una compleja red de disputas fundacionales mediadas por la capacidad de poder viajar sin nada más que su afición y pasión por el equipo de su amores, es decir: la concreción de tener aguante en las carreteras que comunican a distintas ciudades de Colombia.

El sociólogo de la Universidad Nacional, Germán Eliecer Gómez, quien es integrante fundador de la Asociación Colombiana de Investigación y Estudios Sociales del Deporte (ASCIENDE); desarrolla en el año 2001 una de las primeras investigaciones sobre el fenómeno de las barras en la ciudad de Bogotá. Retomando el trabajo de Gómez (2012), define las barras de fútbol como asociaciones de individuos cohesionados por la pasión y el gusto por el fútbol, siendo los procesos identitarios que se construyen lo más interesante de analizar al interior de estas barras. 
Con relación con las condiciones sociales y la violencia juvenil, Aguilar y Muñoz (2015) plantean que la violencia se encuentra asociada a la pobreza, la marginalidad y a los conflictos de índole política que atraviesan a la sociedad colombiana, lo cual conduce a la población juvenil a situaciones de enormes incertidumbres, decepciones y desesperanzas. Sin embargo, afirman que, a pesar de las contrariedades, los jóvenes construyen formas de organización y acción colectiva de resistencia y oposición al modelo económico, que, en el contexto colombiano actual, configuran otras formas para la construcción de la paz.

Por último, es importante mencionar que, en este ejercicio de construir y exponer un estado del arte sobre fútbol, violencia y barrismo, se observa que esta línea de investigación ha sido trabajada en su mayoría por personas de género masculino. Esto indicaría que también en el campo científico están presentes expresiones de masculinidades asociadas al deporte como diría Zambaglione (2011) «temas de machos, para ser investigados por machos». Para finalizar, el recuento de productos académicos da cuenta que, aunque existen copiosas investigaciones sobre barras bravas en Colombia, aún son escasas las que se refieren a los procesos de apropiación simbólica o física por parte de estos colectivos juveniles sobre los territorios, especialmente los caminos o carreteras los cuales no solo comunican ciudades entre sí, también llevan una nueva pasión por el fútbol presente en estos nuevos actores sociales.

Frente a los conceptos de territorio y su apropiación en las organizaciones barristas se pueden destacar publicaciones e investigaciones que abordan el fenómeno fuera del estadio y el espectáculo del fútbol, Salcedo y Rivera (2007) concluyeron que existen para los barristas varias formas de apropiar el territorio, en un espacio simbólico donde se mezclan los recuerdos y las experiencias de pertenecer a la organización, que se transportan desde lo íntimo a lo público, como, por ejemplo; reliquias que se coleccionan en la habitación o lugares de la casa (camisetas del equipo, desprendible de boletas de entrada a partidos, afiches del equipo, entre otros). Y en el espacio público se apropian lugares como parques, esquinas, calles, bulevares de centros comerciales, para establecer sus espacios de interacción y organización en el escenario local. Estos espacios se defienden y se atacan en una constante lucha por el territorio simbólico y real de cada parche o barra local de un equipo de fútbol.

En el trabajo de Clavijo (2010) se concluye como se produce un aguante territorial, a partir de varias formas de organización, que superan la violencia y permiten establecer rituales de apropiación territorial, en la que los integrantes de la barra reconocen como un código simbólico que se representa en la cotidianidad y es funcional en las estrategias logísticas desde el escenario deportivo al espacio barrial y local. 
Otro producto académico relacionado es la monografía de Marroquín (2017), donde se realiza un estudio de las organizaciones barristas en el escenario local en el caso del municipio de Fusagasugá, Cundinamarca, donde se presenta como conclusión del documento la necesidad de establecer estrategias de barrismo social para bajar el impacto en la convivencia de los hinchas guerreados que transitan por el municipio con destino a la ciudad de Bogotá o ciudades del sur de Colombia que tiene equipos en la liga profesional colombiano. A partir de los antecedentes mencionados planteamos la pregunta que fundamenta el proyecto de investigación.

¿Cómo se pueden identificar las expresiones juveniles, recorridos, experiencias de viaje de algunas organizaciones barristas que transitan entre Bogotá, Soacha, Fusagasugá y Girardot, para asistir al espectáculo del fútbol profesional colombiano en el periodo 2015-2019?

\section{TERRITORIO Y APROPIACIÓN TERRITORIAL}

Teniendo en cuenta los objetivos y pregunta problema, el territorio se convierte en una categoría central para explicar las experiencias de viaje para asistir a la fiesta del fútbol, convirtiéndolo en escenario de disputa continua entre el espacio privado, el espacio público y el ciberespacio. Serán los escenarios cotidianos donde confluye el aguante, la organización, las relaciones de género y la violencia, este territorio se desprende de las vivencias, las acciones y la memoria, porque estos espacios se marcan en el cuerpo y el espacio público por medio de grafitis que marcan los lugares de reunión, los territorios en disputa y los territorios apropiados, tal como define el territorio Montañez y Delgado, a continuación:

Territorio se refiere (Geiger, 1996) a una extensión terrestre delimitada que incluye una relación de poder o posesión por parte de un individuo o un grupo social. Contiene límites de soberanía, propiedad, apropiación, disciplina, vigilancia y jurisdicción, y transmite la idea de cerramiento. El concepto de territorio está relacionado con la idea de dominio o gestión dentro de un espacio determinado; está ligado a la idea de poder público, estatal o privado en todas las escalas (Cotreia de Andrade, 1996). (Montañez y Delgado, 1998, p. 124).

El territorio como idea de dominio y relación de poder, establece dinámicas que no manejan tiempos lineales, más bien emergen representaciones del tiempo y espacio, que se desvanecen en las experiencias y las emociones, gestionando un territorio con tiempos divergentes, tal como lo plantea Augé (1993) como no lugares. "Las generaciones se "destemporalizan", creándose "no tiempos" equivalentes a los "no lugares" (Augé, 1993) auténticos "limbos sociales" que pueden ser una estación hacia ninguna parte» (Feixa, 2000, p. 86). 
Este efecto del tiempo en el territorio, generando limbos que se nutren de la memoria, a partir de relatos que permiten con las experiencias de viaje en las estrategias y formas para sobrevivir al riesgo y el vértigo del viaje como guerreado o en viaje organizado por la barra. A este proceso se denomina como territorialización es decir una apropiación del territorio a partir de las emociones como por ejemplo el aguante (Montańez y Delgado. 1998).

\section{INTERACCIÓN CON EL TERRITORIO Y TERRITORIALIZACIÓN A PARTIR DEL AGUANTE}

Las interacciones con el territorio a partir del aguante se convierten en una forma de territorialización, «la superficie de la Tierra está recubierta de territorios que se sobreponen o se complementan, derivando en diversas formas de percepción, valoración y apropiación, es decir, de territorialidades que se manifiestan cambiantes y conflictivas. Las lealtades al territorio nacen del grado de territorialidad y en un mismo espacio se pueden yuxtaponer varias lealtades a distintos actores territoriales» (Montañez y Delgado, 1998, p. 124).

Estas lealtades al territorio se convierten en un vínculo permanente con la organización, el equipo de fútbol y los aspectos simbólicos que representan o significan pertenecer, como los colores de la camiseta, los recuerdos de las experiencias y la fiesta como mecanismo continuo, entre la cotidianidad y los partidos de fútbol. "Como lo explica un hincha, la catarsis en el punto máximo de la celebración, mientras el aguante es una constante que permite la continuidad del ritual y proxémica todos los días de la semana» (Salcedo y Rivera, 2007, p. 58).

En esta catarsis y emociones, se activan también con la velocidad y el riesgo, para los integrantes de las barras futboleras, los viajes que los sitúan en la fiesta, no solo basta con asistir al partido de fútbol y celebrar en el estadio, para tener un mayor aguante es necesario demostrar este sentimiento con sacrificios que permiten apropiar el territorio.

En la experiencia de aguantar el tiempo como lo percibe el sistema capitalista y las personas adultas, es diferente en los hinchas que pertenecen a la organización, reflejando percepciones diferentes a la idea de progreso, entre más compromiso exista con la barra, se alejan de la educación, trabajos formales o compromisos sociales tradicionales. Carles Feixa (2000) plantea las paradojas del tiempo para la juventud, "Todos estos aparatos crean tiempos simultáneos, pero no continuos (es decir, crean una "simultaneidad" completamente artificial). No existe ni el pasado ni el futuro, sino únicamente el presente» (p. 85).

Entonces la experiencia y la memoria componen lo simultáneo, en algunos casos hinchas viajan por meses para asistir a un partido a un país diferente, tomando diferentes riesgos y formas de realizar el viaje. De esta forma, la vida tradicional 
del mundo sedentario se abandona por la sensación nómada de viajar y buscar el punto de llegada en el reto y la dificultad de lograr el propósito, para los hinchas se tiene mayor aguante si existió mayor resistencia y oposición a sus objetivos, algunos de ellos prefieren viajar en pequeños grupos evitando la organización preestablecida de la barra, como vuelos aéreos y transporte terrestre autorizado.

El aguante permite que la interacción del territorio sea una demostración que además de la memoria de las experiencias, presenta marcas en el cuerpo, como cicatrices de confrontaciones contra otros hinchas, la autoridad, o actores locales que no toleran las formas de expresión y las estéticas de los viajeros del fútbol, en estos movimientos por el territorio se realizan con el mínimo de recursos económicos, generando un mayor sacrificio que alimenta el aguante.

\section{CONFIGURACIÓN DEL TERRITORIO}

A partir del proceso de territorialización se produce la configuración del territorio, por parte de las organizaciones de jóvenes aficionados a un equipo de fútbol, esta relación requiere varios compromisos y estrategias para demostrar el vínculo emocional. En este proceso se realizan actividades de preparación logística para asistir al espectáculo y establecer algunas normas para llevar a cabo la fiesta, que se fragmenta en el tiempo.

La logística de la organización es compleja, porque apropia el territorio y está conformado por una jerarquía vertical en la dirección de la barra, de carácter nacional y regional y con horizontalidad en los escenarios locales como el barrio (Salcedo y Rivera, 2007). Por lo tanto, existe una logística para el manejo de las emociones y la fiesta, que establece unos roles con mayor compromiso y riesgo, generando retos y pruebas de fidelidad y amor. Se observan relatos épicos y narrativas heroicas de lo que se es capaz de hacer por su organización, tal como Hall (1996) lo relaciona con las identidades:

Las identidades, en consecuencia, se constituyen dentro de la representación y no fuera de ella. Se relacionan tanto con la invención de la tradición como con la tradición misma, y nos obligan a leerla no como una reiteración incesante sino como «lo mismo que cambia» (Gilroy, 1994) no el presunto retorno a las raíces sino una aceptación de nuestros «derroteros». Surgen de la narrativización del yo, pero la naturaleza necesariamente ficcional de este proceso no socava en modo alguno su efectividad discursiva, material o política, aun cuando la pertenencia, la «sutura en el relato» a través de la cual surgen las identidades resida, en parte, en lo imaginario (así como en lo simbólico) y, por lo tanto, siempre se construya en parte en la fantasía o, al menos, dentro de un campo fantasmático (Hall, 2003, p. 18). 
Estas fantasías y relatos permiten motivar las actividades y tareas para defender la organización o atacar a otra barra rival como expresión de superioridad; algunas de estas tareas tienen que llevar violencia y riesgo que se basa en la fuerza, mientras que otras acciones se derivan de las habilidades manuales en la elaboración de banderas o trapos y otras más se encargan de realizar trabajos de inteligencia para saber lo que hacen el enemigo y las fuerzas de orden.

Teniendo en cuenta a Bauman (1996), estas estructuras y roles se convierten en una norma y una práctica cotidiana que no se cuestiona por los integrantes, pero establece certezas y lógicas que permiten pertenecer a partir de estas pautas. En palabras de Bauman:

Pensamos en la identidad cuando no estamos seguros del lugar al que pertenecemos; es decir, cuando no estamos seguros de cómo situarnos en la evidente variedad de estilos y pautas de comportamiento y hacer que la gente que nos rodea acepte esa situación como correcta y apropiada, a fin de que ambas partes sepan cómo actuar en presencia de la otra (2003, p. 42).

En las organizaciones juveniles barristas, estas pautas de comportamiento y códigos simbólicos, que se comunican desde la organización general y se practican en los parches o grupos locales que permanecen en el escenario local, son reconocidas. Carles Feixa (2000) lo denomina como microculturas, porque adaptan estas narrativas, códigos, roles y jerarquías, configurando el territorio desde la función y lo simbólico. Sin embargo, esta organización activada en las emociones y los relatos funciona a partir del vértigo, la velocidad, en una mezcla de sentimientos, que nutren la memoria y se convierten en ese apego y motivación que, para los especialistas en barras futboleras, se denomina «el aguante por el equipo y la barra».

\section{RUTA Y ACLARACIONES METODOLÓGICAS}

El enfoque epistemológico y teórico práctico propuesto para el desarrollo de la investigación es la etnografía, que se refiere a la reflexividad y el reconocimiento de la complejidad de la vida cotidiana, en este caso de las interacciones que ocurren entre las juventudes. El modelo investigativo propuesto presenta una estrategia metodológica que consta de tres fases: (i) selección de informantes, fuentes de datos y estrategias de recolección de información; (ii) trabajo de campo, y (iii) análisis de la información (Urbina, 2011, pp. 169-177).

Una etnografía del territorio no significa la inserción de las narrativas en el discurso antropológico como aliadas testimoniales, sino en la conjugación de dos formas de representación e interpretación de la realidad que no son distantes en sus teorías, métodos, cuestionamientos y visiones, y que posibilitan un acercamiento 
multisensorial a los contextos, sujetos y objetos de su estudio, lo que no solo permite indagar desde el instante que proponen, sino además desde las memorias que evocan, abriendo distintos espacios y temporalidades para la interlocución con los observadores.

Para una investigación etnográfica sobre las memorias sociales, son de gran importancia la acción de registrar y la reflexión posterior sobre lo que se registra, por lo cual, vamos entonces tras la evidencia narrativa en términos de su soporte fotográfico, diarios de campo, sistematización de narrativas de los actores en el territorio, se propone un análisis denso de la cotidianidad desde las interacciones sociales de los protagonistas que dialogan sobre los guerreados.

Las fases de la investigación se encuentran articuladas a los objetivos específicos de la siguiente forma:

- Fase 1. Selección de puntos de referencia de interacción de los hinchas guerreados para identificación de rutas y recorridos de organizaciones barristas.

Se seleccionaron puntos de referencia, a partir de los relatos de las experiencias y anécdotas de los recorridos de algunas organizaciones barristas en la ciudad de Bogotá y los municipios de Soacha, Fusagasugá y Girardot durante el período 2018-2019. Para ello, se realizó un acercamiento a las fuentes de datos nacionales como el Departamento Nacional de Estadística (DANE), la información local de instituciones oficiales, bases bibliográficas de universidades y revistas académicas.

Con la información recolectada y sistematizada, se han realizado salidas de campo, donde a través de la herramienta del Sistema de Posicionamiento Global (GPS) se tomarán los puntos geográficos de los diferentes sitios de encuentro e interacción de los grupos barristas, en el recorrido vial entre Bogotá, Soacha, Fusagasugá y Girardot, teniendo en cuenta las enunciaciones y relatos para establecer el territorio y la territorialidad de los hinchas que participaron en el proyecto.

- Fase 2. Identificación de subjetividades a partir de experiencias, sentimientos, vivencias, trayectorias vividas.

Para caracterizar las expresiones juveniles que se generan en los recorridos de la ruta Bogotá, Soacha, Fusagasugá y Girardot por los hinchas, se ha puesto en operación una serie de métodos de investigación, como la etnografía, cartografía e historias de vida, que permitirán generar ejercicios de reflexividad en los sujetos. Esta serie de métodos se entiende como instrumentos de investigación que permiten abrir un espacio para comprender las expresiones generadas de las experiencias, sentimientos, vivencias, análisis, formas de ser, creer, pensar, actuar, sentir y relacionarse, de los considerados barristas. De esta manera, activan mecanismos de participación y diálogo (Ghiso, 2002). Es decir, los jóvenes, a fin de tejer un ejercicio de construcción dialógica, son quienes comienzan a interpretar 
los recorridos y la apropiación de los territorios como transeúntes y como hinchas que habitan permanentemente el corredor de entrada y salida sur de Bogotá.

Para tal efecto, se han realizado unos acercamientos a las interacciones comunicativas de los jóvenes mediante el ejercicio de las entrevistas, lo cual ha permitido reconocer experiencias y narrativas de viaje.

A continuación, se describe sucintamente el desarrollo metodológico para alcanzar el objetivo propuesto:

a. Observación participante: (i) seguimiento de las interacciones entre los jóvenes en los recorridos de viaje; (ii) organización de los recorridos, lugares de encuentro, formas de convivencia y estrategias de movilidad, y (iii) diario de campo.

b. Cartografía: (i) tomar y sistematizar puntos clave y representativos del recorrido vial, donde se presenten interacciones de los grupos barristas, no solo en clave de violencia sino en diferentes tipos de actividades.

c. Entrevistas semiestructuradas con el formato de "historias de vida» se realizaron a hinchas de diferentes barras y regiones.

- Fase 3. Narrativas y experiencias de viaje de organizaciones barristas.

A partir de los productos obtenidos en las dos fases anteriores, se construyen las narrativas sobre las experiencias de viaje de algunos actores que conforman organizaciones barristas. Estos relatos de viaje permiten configurar la manera en que perciben y viven el territorio, estableciendo diferentes formas del aguante en la territorialidad y configuración de los recorridos, en el tiempo y en el espacio.

\section{ACtividades ReAlizadas Del PROYeCto}

Las actividades que se han realizado han estado orientadas en dos direcciones: la primera, en cumplimiento con el primer objetivo del proyecto con la búsqueda sistemática y organizada de estudios académicos y gubernamentales, relacionados con el fenómeno de las barras futboleras y las rutas de viaje de estas organizaciones juveniles por el territorio colombiano. Las otras actividades están orientadas al cumplimiento del segundo y tercer objetivo del proyecto, donde se han realizado dos salidas de campo por el recorrido vial de Bogotá, Soacha, Fusagasugá y Girardot, donde se han aplicado actividades de recolección de información a través de entrevistas y toma de puntos de referencia geográfica. También se han realizado cuatro entrevistas a integrantes de diferentes organizaciones barristas de los equipos Atlético Nacional, América de Cali, Millonarios e Independiente Santa Fe.

Otras actividades paralelas y transversales al cumplimiento de los objetivos de proyecto han sido las reuniones realizadas por los miembros del grupo de 
investigación. En cada una de las reuniones del grupo, se han abordado y trabajado diferentes asuntos logísticos, administrativos e investigativos del proyecto.

\section{RESULTADOS PRELIMINARES}

\section{Salidas de campo}

La primera salida a campo se realizó entre el 12 y 13 de octubre de 2018. En esa ocasión asistieron todos los miembros que conforman el grupo de trabajo del proyecto, con el fin de hacer un reconocimiento de cada miembro, definir la agenda de trabajo, y realizar un primer recorrido vial. El primer día se realizó una reunión en el municipio de Fusagasugá, donde se encuentra una sede de la Universidad de Cundinamarca. En la reunión se dio un repaso a la formulación, objetivos del proyecto — como la planeación de un cronograma de trabajo—, y asuntos administrativos y económicos del proyecto.

Para el día 13 de octubre en horas de la mañana se inició el reconocimiento de la ruta vial entre Bogotá, Soacha, Fusagasugá y Girardot. Los objetivos a cumplir eran hacer un primer reconocimiento a la ruta e identificar puntos estratégicos donde se presentarán interacciones entre las barras de fútbol con actores externos como vendedores, habitantes de los municipios, conductores, agentes policiales, etc.

En las visitas de campo se pudieron evidenciar diferentes características en puntos críticos y estratégicos de señalización y también se resaltaron dos tipos de grupos de barristas: por un lado, los que viajan de manera organizada en buses y con las boletas adquiridas para ingresar al estadio, y otros hinchas que viajan en grupos pequeños en condiciones de alto riesgo, como por ejemplo; los que se movilizan en la parte trasera de un tractocamión o caminando por la carretera. A este tipo de hinchas se le conoce como caminantes o guerreros de la carretera (ver foto 2).

En los viajes de reconocimiento se establecen lugares críticos donde se realizan paradas obligatorias, como el caso de los peajes de Chusacá y Chinauta (fotos 3 y 4). En estos lugares los barristas revisan la estrategia para subirse a las tractomulas (vehículos de carga pesada), o los autobuses se detienen para que los hinchas realicen un descanso en el viaje.

Algunos informantes indicaron que en ocasiones se consuman enfrentamientos y se generan robos a los locales comerciales de estos lugares de comestibles y bebidas, además se evidencian marca de los hinchas que se hace por medio de grafitis mostrando su paso y dominio en el territorio (fotos 5 y 6 ). 


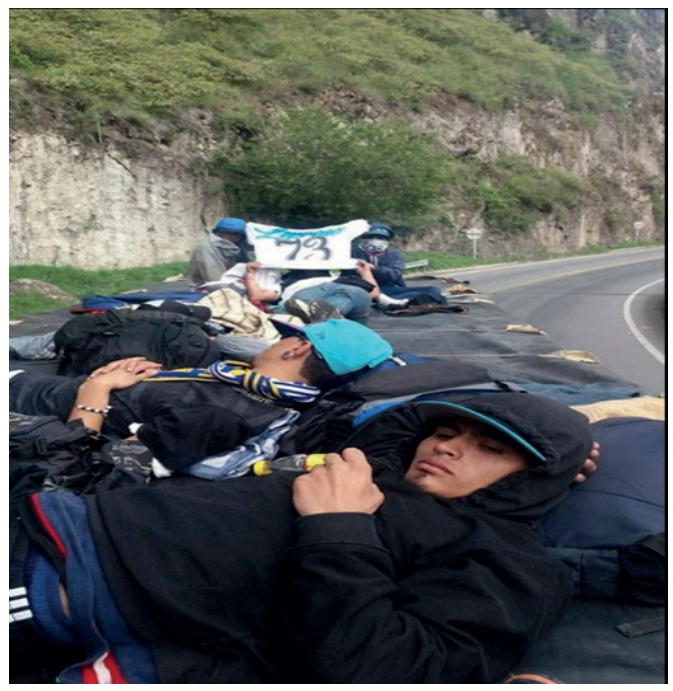

Foto 2. Hinchas de Millonarios, vía entre el Alto del Trigo y Guaduas Cundinamarca. Tomada por Sergio Andrés Caro (2019).

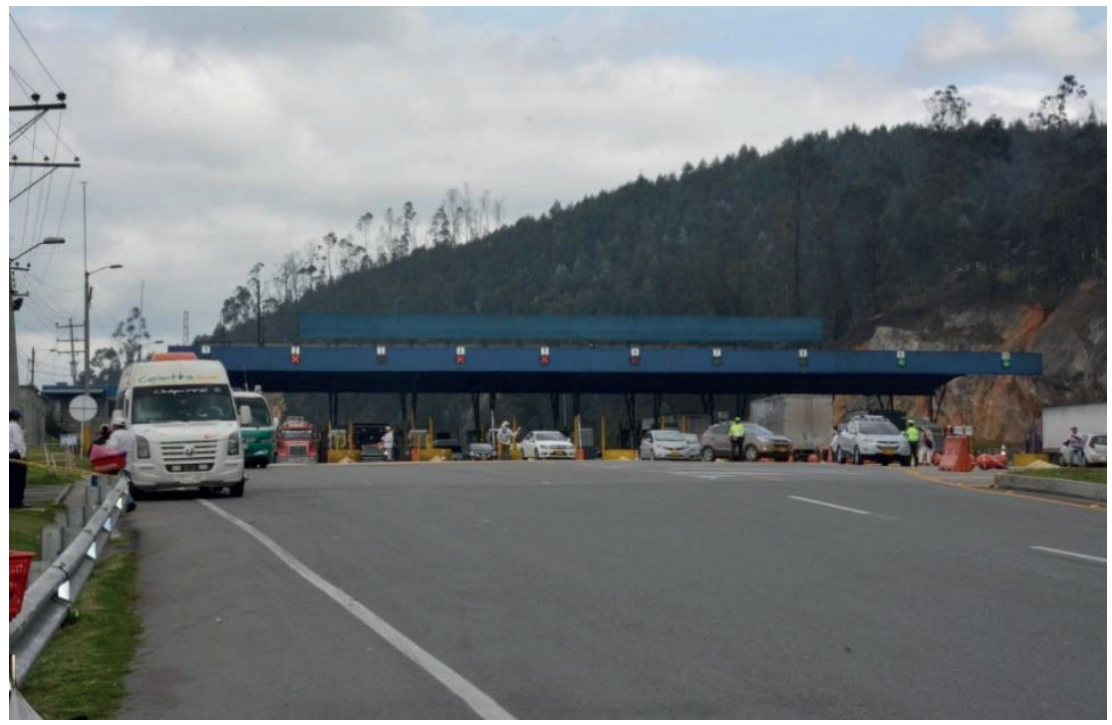

Foto 3. Peaje Chuzacá, vía Bogotá-Girardot. Tomada por Alejandro Villanueva (2018). 


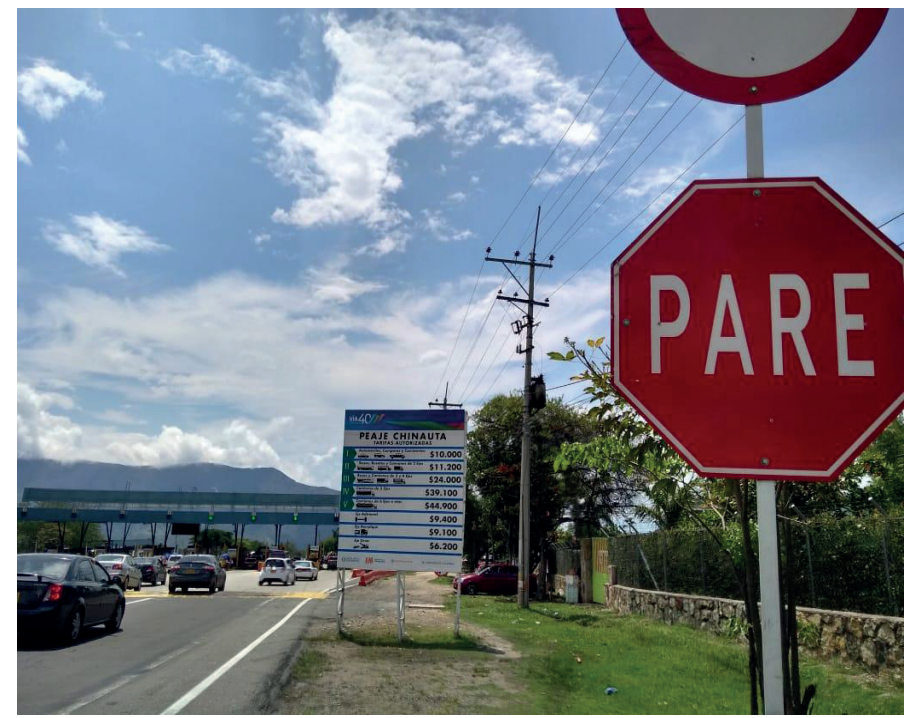

Foto 4. Peaje de Chinauta, vía Bogotá-Girardot. Tomada por Alejandro Villanueva (2018).

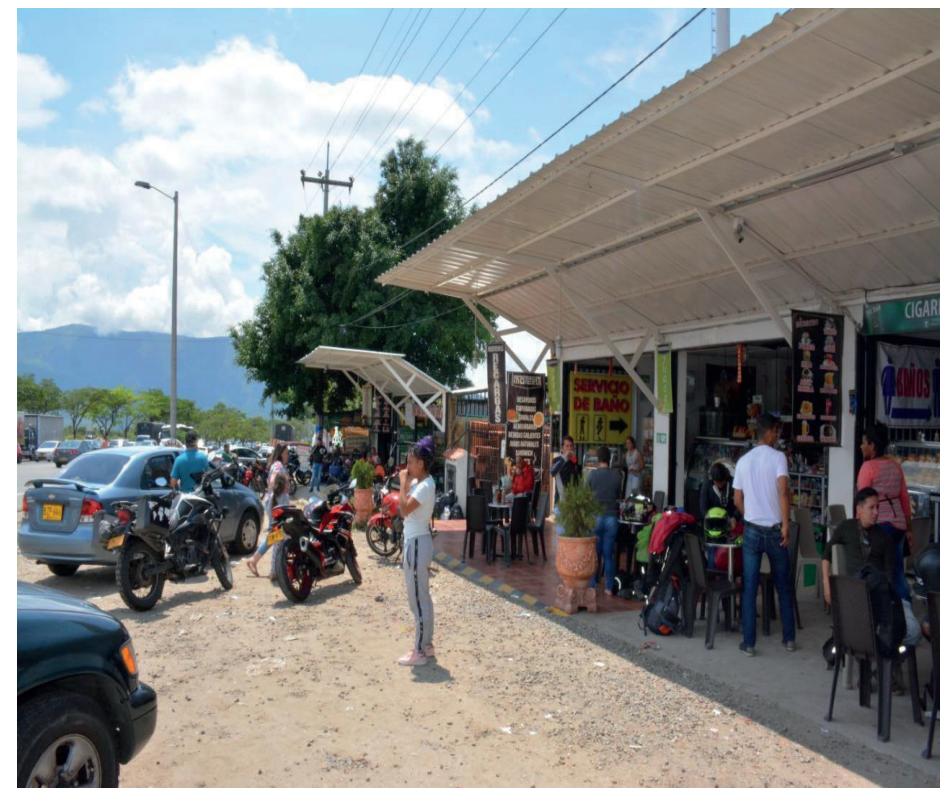

Foto 5. Zona comercial del peaje Chinauta-Cundinamarca. Tomada por Alejandro Villanueva (2018). 


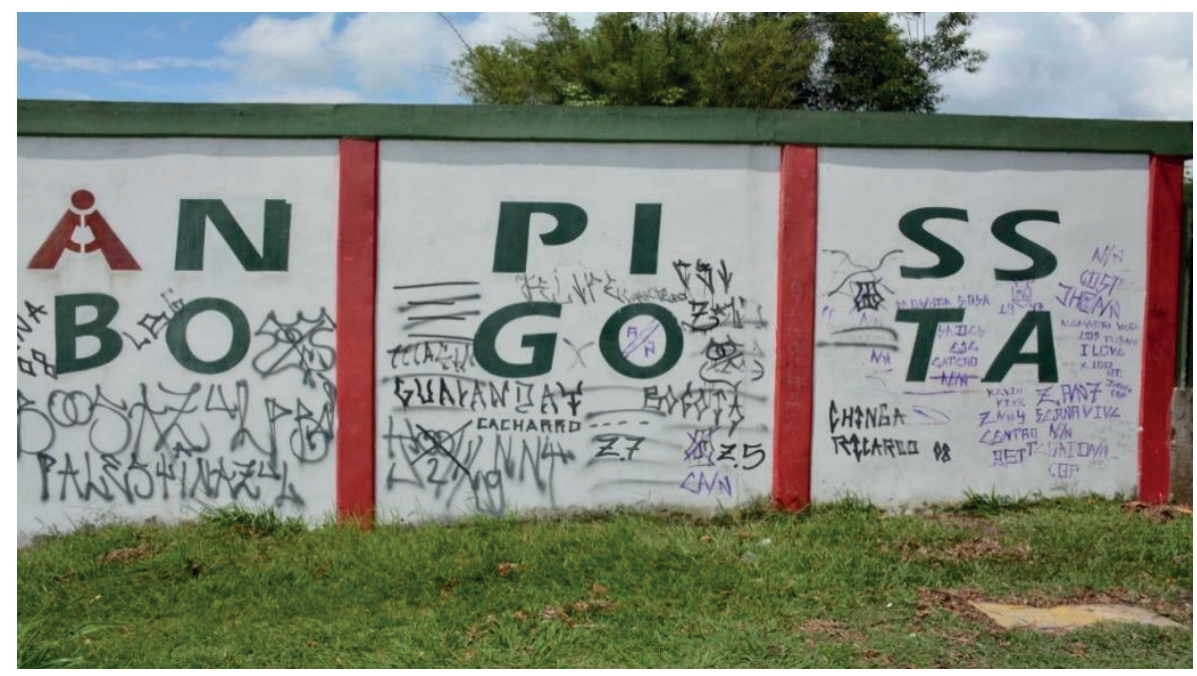

Foto 6. Alrededores del peaje de Chinauta-Cundinamarca. Tomada por Alejandro Villanueva (2018).

El sábado 17 de noviembre se desarrolló la segunda salida a la ruta Bogotá, Soacha, Fusagasugá y Girardot. La salida se sincronizó con el partido de vuelta de la semifinal del torneo colombiano, entre Tolima e Independiente Santa Fe, disputado en la ciudad de Ibagué, estadio Manuel Murillo Toro. El objetivo principal de la salida fue recolectar puntos de referencia geográfica de escenarios donde se evidencian expresiones barristas de diferente carácter, ya sean culturales, económicas o violentas.

En la salida se tomaron puntos de georreferenciación con la herramienta GPS (Sistema de Posicionamiento Global) y se realizaron registros visuales del recorrido. El registro de cada punto se consensuó por el conocimiento y experiencia que los investigadores ostentan del fenómeno del barrismo. Los resultados fueron trece registros de georreferencia, con su respectivo registro visual.

A continuación, presentamos el mapa 1 que plasma el recorrido y los puntos de referencia tomados, y una tabla con los datos recolectados y su observación. 


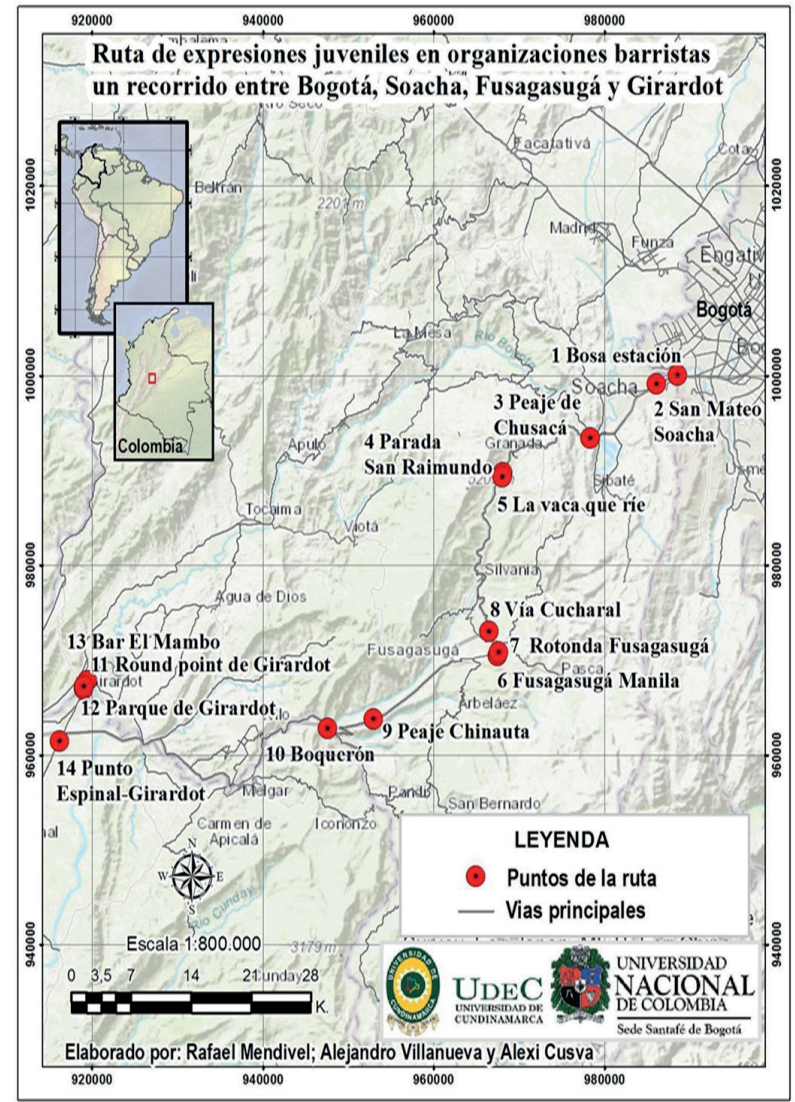

Mapa 1. Puntos relevantes con dinámicas e interacciones de las organizaciones barristas

Tabla 1. Puntos de georreferenciación tomados en las salidas de campo

\begin{tabular}{|c|c|c|}
\hline Referencia & $\begin{array}{l}\text { Ubicación } \\
\text { geográfica }\end{array}$ & Categoría de expresión \\
\hline \multirow{2}{*}{ 1. Bosa estación } & $\mathrm{N} 4^{\circ} 35.825$ & *Punto de encuentro de barrista \\
\hline & W $74^{\circ} 10.825$ & * Expresiones simbólicas- grafitis. \\
\hline \multirow{2}{*}{ 2. San Mateo Soacha } & N $4^{\circ} 35.127$ & *Punto de encuentro de barrista \\
\hline & W $74^{\circ} 12.436$ & * Expresiones simbólicas- grafitis \\
\hline \multirow[b]{2}{*}{ 3. Peaje de Chusacá } & $\mathrm{N} 4^{\circ} 32.201$ & \multirow{2}{*}{ * Punto para realizar subida a mulas } \\
\hline & W $74^{\circ} 16.355$ & \\
\hline \multirow[b]{2}{*}{ 4. Parada San Raimundo } & $\mathrm{N} 4^{\circ} 30.210$ & * Comercio \\
\hline & $\mathrm{W} 74^{\circ} 21.890$ & $\begin{array}{l}* \text { Rebusque } \\
* \text { Alimentación }\end{array}$ \\
\hline
\end{tabular}




\begin{tabular}{|c|c|c|}
\hline Referencia & $\begin{array}{l}\text { Ubicación } \\
\text { geográfica }\end{array}$ & Categoría de expresión \\
\hline \multirow{2}{*}{ 5. La vaca que ríe } & $\mathrm{N} 4^{\circ} 29.990$ & ${ }^{*}$ Rebusque \\
\hline & W $74^{\circ} 21.927$ & * Comercio \\
\hline \multirow{4}{*}{ 6. Fusagasugá Manila } & $\mathrm{N} 4^{\circ} 19.786$ & *Punto de encuentro (barra de millonarios) \\
\hline & \multirow{3}{*}{ W $74^{\circ} 22.164$} & * Expresión grafitis \\
\hline & & * Apropiación de espacio \\
\hline & & ${ }^{*}$ Consumo de drogas \\
\hline \multirow{4}{*}{ 7. Rotonda Fusagasugá } & \multirow{2}{*}{$\mathrm{N} 4^{\circ} 19.974$} & *Punto de encuentro (barra de millonarios) \\
\hline & & * Expresión grafitis \\
\hline & \multirow{2}{*}{ W $74^{\circ} 22.164$} & ${ }^{*}$ Apropiación de espacio \\
\hline & & * Consumo de drogas \\
\hline \multirow{2}{*}{ 8. Vía Cucharal } & $\mathrm{N} 4^{\circ} 21.135$ & \multirow{2}{*}{$\star$ Punto de encuentro para conseguir transporte } \\
\hline & W $74^{\circ} 22.765$ & \\
\hline \multirow{6}{*}{ 9. Peaje Chinauta } & \multirow{3}{*}{$N 4^{\circ} 16.161$} & *Punto de encuentro \\
\hline & & * Consumo de alimentos \\
\hline & & * Recateo \\
\hline & \multirow{3}{*}{ W $74^{\circ} 30.046$} & ${ }^{*}$ Grafitis \\
\hline & & *Violencia \\
\hline & & *Subida a camiones \\
\hline
\end{tabular}

10. Boquerón

$\mathrm{N} 4^{\circ} 15.579$

W $74^{\circ} 32.999$

\begin{tabular}{|c|c|c|}
\hline $\begin{array}{l}\text { 11. Glorieta entrada de } \\
\text { Girardot }\end{array}$ & $\begin{array}{l}\text { N } 4^{\circ} 18.289 \\
\text { W } 74^{\circ} 48.205\end{array}$ & * Punto de encuentro \\
\hline \multirow{2}{*}{ 12. Parque de Girardot } & $\mathrm{N} 4^{\circ} 18.289$ & *Punto de encuentro \\
\hline & W $74^{\circ} 48.205$ & ${ }^{*}$ Grafitis \\
\hline \multirow[b]{2}{*}{$\begin{array}{l}\text { 13. Bar de barristas de } \\
\text { Nacional }\end{array}$} & $\mathrm{N} 4^{\circ} 18.011$ & * Punto de encuentro \\
\hline & W $74^{\circ} 48.436$ & $\begin{array}{l}\text { * Consumo de alcohol-drogas } \\
{ }^{*} \text { Consumo de espectáculo deportivo }\end{array}$ \\
\hline
\end{tabular}

En los trece puntos priorizados inicialmente en el recorrido, se han reconocido algunas categorías de expresión que ocurren en estos sitios estratégicos que forman parte de las prácticas barristas (grafitis, fronteras invisibles, lugares de descanso 
y socialización y espacios de conflicto), estos datos se han venido consolidando, constatando y definiendo con los hinchas y residentes de estos, sectores, los cuales manifiestan percibir el impacto de este nuevo fenómeno social, cultural y juvenil en la carretera y espacios de intersección de los distintos municipios atravesados por estas rutas futbolizadas de la convivencia, conflicto y socialización de muchos jóvenes bogotanos y cundinamarqueses.

\section{LOS GUERREROS DEL CAMINO UNA APROXIMACIÓN A NUESTROS PROTAGONISTAS}

Ricardo Romero ${ }^{1}$ tiene veintiséis años y estudia en la Universidad de Cundinamarca. Habita en la ciudad de Fusagasugá, pertenece a la barra del Disturbio Rojo del América de Cali y su vinculación con el equipo proviene de su infancia. Ha realizado viajes por diferentes ciudades con su parche, que es de Bogotá. Realiza viajes periódicos hasta a la capital para reunirse con sus amigos desde Fusagasugá.

Elkin Suarez tiene veinticinco años, es hincha de Millonarios, vive en la localidad de Ciudad Bolívar de Bogotá D. C, se financia los estudios a través de una plataforma de domicilios en bicicleta y viajó durante varios años acompañando a su equipo dentro y fuera del país, aplazando su carrera en una universidad pública de Bogotá. Dejó los viajes para culminar sus estudios y evalúa estas experiencias como un proceso de formación personal a partir las experiencias como guerrero del camino.

Federico Garca, con veintiséis años de edad, es hincha de los del Sur del Atlético Nacional desde los doce años de edad, habita en Girardot, Cundinamarca, es líder de un parche con habitantes de este municipio y estudiante de Ingeniería de Sistemas. Este parche trabaja estrategias de barrismo social y sus integrantes viajan de manera organizada por Colombia.

\section{Aproximación de algunas características de las expresiones de las barras futboleras del hincha viajero o guerreado}

A partir de las historias de vida de los hinchas que han venido participando como informantes del proyecto, se pueden establecer varias formas de expresión que se presentan en las experiencias de viajes, a partir de las dificultades, riesgos y peligros que han llevado varias vidas de jóvenes en las carreteras de Colombia y Suramérica. Por otra parte, la experiencia de viajar como prueba de iniciación en el aguante que demuestra el amor por el equipo. Como lo expresa Ricardo Romero, hincha del América de Cali, sobre los motivos para realizar un viaje como visitante: « $L a$ pasión que cada uno le meta, lo que lo mueve a uno de ir a la cancha y meterle toda la energia a la mechita y por satisfacción personal, a mi por lo menos me llena!».

\footnotetext{
1 Los nombres de los protagonistas han sido cambiados.
} 
La emoción por el equipo es la motivación más relevante, cuestión que permite entender cómo se diferencian las expresiones a partir de la experiencia de viaje, en primera instancia como viaje organizado por el colectivo barrista, como sucede en la barra Disturbio Rojo del América de Cali, que contrata buses y compran las boleta para ingresar al estadio con anterioridad al partido y establecen estrategias y logística como colectivo para realizar viajes como visitantes o locales en la ciudad de Cali u otras ciudades. Estos viajes organizados se derivan a una jerarquía de la barra y tienen unos costos diferenciados dependiendo su rol, tal como lo describe Ricardo.

Siempre hay viajes, de los buses es la gente de la misma barra, viajan harto también en buses de la empresa Tres Reyes, vale 60 lukas, hasta Cali, ahora la barra está organizada, aunque, los viajes a la Costa valen más, hasta $\$ 500.000$, y sacan planes para viajar hasta al extranjero. Los chinos referentes gestionan y botan la información. En esa jerarquía varían los precios: unos no pagan, otros pagan $\$ 60.000$ o $\$ 30.000$, unos de pie, en severa farra, jaja!, y los conductores son conocidos.

Pero en este proceso se pueden encontrar hinchas que no disponen de la capacidad económica ni las relaciones con la jerarquía de la barra para realizar los viajes. En este caso, toman la decisión de ir sin las condiciones de la organización, y además, evadiendo las políticas de las ciudades que restringen los hinchas de equipos visitantes. Por esta razón, a este tipo de hinchas se les denomina guerreados o guerreros del camino.

Las expresiones de un hincha guerreado se refieren a la estrategia para viajar, que tiene que ver con formas para sobrevivir con el menor costo posible, y exterioriza la experiencia de viaje al máximo nivel, expresado como aguante o pasión por equipo, con mayor intensidad, y cada viaje es una forma de sentir mayor capacidad de ser hincha y tener autoridad sobre su rol en las emociones de compartir con otros.

Para Elkin Suárez, hincha guerreado de Millonarios, viajar requiere técnicas y conocimientos para subir a una tractomula, y de estos aprendizajes depende la vida y la integridad física por los riesgos que implica buscar esta forma de transportarse. De esta manera, Sergio describe la práctica y experiencia de trepar la mula de la siguiente manera:

Eso también digamos que tiene su técnica, porque usted tiene que estar pendiente de muchos factores y estos factores indudablemente no los conocen al principio las personas que entran a esta práctica, y por esta razón, también es que se han producido varias muertes, no porque no se saben subir a la mula, sino porque no saben cómo correr a la mula para subirse.

Ricardo Romero también describe su experiencia como guerreado con la siguiente narración: 
Una vez fui a Villavicencio, íbamos seis hombres y una nena, nos subimos en Yomasa, buscamos que en el lugar fuera la mula lento. Siempre está el rigor porque en el camino se puede encontrar uno otra banda... se sube uno en los peajes y reductores de velocidad, a lo maldita sea se va uno subiendo. Hay muleros re bien que no dicen nada y hay otros que esperan encontrar un policía y lo bajan.

En esta experiencia se encuentra el vértigo y se puede denominar como una forma de vida, que para muchos de estos hinchas implica dejar todo para seguir a su equipo y viajar no solo por Colombia, sino también por países de Sudamérica, donde se juegan partidos de la Copa Libertadores de América, Copa Sudamericana, eliminatorias al Mundial, entre otros partidos que pueden implicar entre uno y seis meses para realizar ida y regreso. En algunas ciudades, los hinchas trabajan de forma informal para sobrevivir y continuar el viaje.

Elkin Suárez expresa una decisión crucial en torno a su pasión por seguir y alentar a Millonarios, al aplazar la universidad y suspender sus estudios varios semestres para ir a viajes internacionales, cuestión que luego de los años le generan varias reflexiones sobre lo que debía pasar con su vida y su proceso de alejamiento de ser hincha guerreado y seguir su carrera como licenciado en deporte: «Sí, tuve que aplazar mis estudios por la pasión, indudablemente esa es la otra parte, que toca dejar a su familia, toca dejar diferentes cosas. Por ejemplo, a mí me gusta el futbol, practico mucho esta actividad, y pues durante estos viajes no podía hacerlo, era muy difícil por muchos motivos».

Estos motivos tienen que ver con pasiones y sentidos sobre el progreso, cuestión que pone en crisis en los sistemas educativos tradicionales, porque muchos de estos hinchas prefieren seguir su llamado en la barra por algún tiempo, dejando la educación media, bachillerato y universitaria para seguir el sueño de libertad de vivir por el fútbol y el equipo de los amores.

En el caso de Federico García, estudiante de Ingenierías de Sistemas e integrante de la barra de Atlético Nacional, denominada «Los del sur Girardot», presenta otras experiencias barristas. Partiendo de entender por qué ingresó a la barra y las motivaciones que los llevaron a ser hincha de Atlético Nacional, él describe:

Ese sentimiento por Nacional creció desde los doce años. Conocí a un amigo y ese amigo me hizo integrar acá y me dijo que fuéramos a un partido, y en ese entonces hasta ahora se estaba iniciando este proyecto, esta unión familiar, porque nosotros decimos es una unión familiar [...] en 2012, y desde ese entonces inició este proceso que hemos llevado a cabo acá en Girardot que hasta el día de hoy ha cambiado muchas expectativas hacia el barrismo. Mi sentimiento por Nacional creció pues porque no se conoce solo a un equipo y a una hinchada, sino también a valorar muchas cosas como la amistad, y hasta ahora uno se refiere a eso porque uno ha pasado por muchas cosas y problemas. Hemos llegado también a 
arriesgar la vida. Entonces es ahí cuando uno dice que los amigos se ven y en esto he aprendido a diferenciar que en esto del barrismo sí hay amigos. A mí me pasó porque en una pelea recibí siete puñaladas que, como quien dice, si no fuera por ese amigo que se metió hubiera colgado los guayos.

Es necesario precisar que el proyecto está en proceso de terminación, y como elemento central se están realizando las narrativas de viaje como historias del amor por equipo, pero también como proceso de cambio en la consecución de subjetividades juveniles a subjetividades de la vida adulta con las responsabilidades como la familia y el trabajo.

\section{Conclusiones}

El proyecto presenta varias conclusiones que se derivan del balance de implementación a partir de los objetivos específicos propuestos. El primero de ellos es «localizar los trayectos viales que toman las barras futboleras para su movilidad entre Bogotá y los municipios de Soacha, Fusagasugá y Girardot». Se puede inferir que se localizaron puntos estratégicos en el uso del territorio funcional y simbólico en lugares apropiados y en disputa permanente, como por ejemplo los peajes de Chusacá y Chinauta, en la carretera y en la ciudad de Bogotá, sitios como la estación de Bosa, el Cementerio el Apogeo y el puente peatonal de Soacha, entre otros escenarios de territorialidad entre lo urbano y lo rural.

Estas configuraciones de viaje permiten evidenciar las diferentes formas de experiencia que derivan del sacrificio y el vértigo en alcanzar la meta de acompañar al equipo de los amores a cualquier lugar que sea necesario, en estos puntos se pueden diferenciar pautas o secretos para lograr colarse en una tractomula o camión de carga que, gracias a un acuerdo con el conductor o como polizones, avanzan algunos kilómetros, caminando y buscando la forma de seguir en la carretera.

El siguiente objetivo específico se refiere a "caracterizar y comprender expresiones juveniles que se generan en los recorridos viales de las barras futboleras entre Bogotá y los municipios de Soacha, Fusagasugá y Girardot». Luego de reconocer las dinámicas espaciales de las rutas y recorridos de los guerreros del camino, se caracterizan por las estrategias para definir el territorio, su apropiación en la territorialidad y su configuración en los espacios públicos y privados.

Estas expresiones de apropiación del territorio ocurren a partir del aguante, cuya temporalidad aumenta en el viaje, en los recuerdos y las experiencias. Estos sufrimientos y velocidades se convierten en aprendizajes para sobrevivir y estas batallas ganadas generan la capacidad de lograr mayor respeto y amor por su equipo, porque no es solo un deporte: es un estilo de vida, con expresiones propias y sentidos de progreso diferentes de la sociedad adulta que proviene de la modernidad. En esta 
investigación se reconoce un aguante alargado en el tiempo y en el espacio que supera la definición del aguante a partir de la fiesta e identidades revisadas en investigaciones anteriores.

Y el tercer objetivo específico se refiere a «reconstruir narrativas de viajes y experiencias de hinchas y su relación con los territorios recorridos». En las historias de vida recopiladas en el proceso investigativo, se pueden evidenciar cambios entre la idea de tiempo y el espacio de la organización barrista, que se derivan de la territorialización y la emoción de alargamiento de la experiencia a partir del viaje. En estos relatos se enuncian cambios en la vida y recuerdos que transitan entre el heroísmo y la capacidad de sobrevivir y las historias de los compañeros que no lograron llegar a su destino y fallecieron en accidentes por el riesgo de estas prácticas de guerrear, o por enfrentamientos violentos en algunos escenarios de encuentro en la carretera.

Estas historias son las que permiten que un guerreado encuentre la capacidad de alejarse y dejar de viajar, para asumir los tiempos de la vida adulta en la proyección profesional y familiar, en un viajero que regresa, que se aleja desde la reflexión y las lecciones aprendidas en algunos casos, mientras otros informantes continúan alentando desde el barrismo social en acciones de convivencia y paz, organizando viajes con normas y reglas en seguridad y cuidado de la vida, de forma colectiva, como por ejemplo el informante de Girardot Cundinamarca.

En última instancia, una de las grandes y más importantes preocupaciones de la academia debe ser evidenciar o denunciar las distintas situaciones de vulneración de los derechos fundamentales de la población colombiana, reflexionando en particular en una problemática, tal como el fenómeno de las barras bravas y cómo, en la última década — según cifras de la CNSCF (Comisión Nacional de Seguridad Comodidad y Convivencia en el Fútbol)—, han perdido la vida en las carreteras de Colombia más de cincuenta hinchas en los últimos diez años.

\section{REFERENCIAS}

Aguilar, N. y Muñoz, G. (2015). La condición juvenil en Colombia: entre violencia estructural y acción colectiva. Revista Latinoamericana de Ciencias Sociales, Niñez y Juventud, 13(2), 1021-1035. https://doi.org/10.11600/1692715x.13233090913

Alabarces, P. (2012). Entre la banalidad y la crítica: perspectivas de las ciencias sociales sobre el deporte en América Latina. En Estudios socioculturales del deporte. Desarrollos, tránsitos y miradas (pp.41-61). Armenia: Kinesis.

Amaya, A. y Villanueva, A. (2011). Goles en paz: crónica de una década. Alcaldía Mayor de Bogotá: Secretaría de Gobierno.

Amaya, A. y Villanueva, A. (2010). Los hinchas de la hinchada [tesis para optar al título de magíster en Educación]. Bogotá: Universidad Pedagógica Nacional. 
Bauman, Z.t (2003). De peregrino a turista, o una breve historia de la modernidad. En S. Hall y P. du Gay (comps.), Cuestiones de identidad cultural. Buenos Aires: Amorrortu,

Cabrera, N. (2012). Violencia e identidad en una hinchada de fútbol: «solo para entendidos» [tesis de licenciatura]. Córdoba: Universidad Nacional de Villa María.

De la Lama, S. (2011). Factores de vulnerabilidad para desarrollar una adicción. Elementos para su prevención. Revista digital Academia, 1, 27-66.

Hall, S. (2003). Introducción: ¿quién necesita identidad. Cuestiones de identidad cultural, 13-39.

Feixa, Carles (2000). Generación @ La juventud en la era digital. Nómadas (Col), (13), 75-91.

Ferrándiz, F. y Feixa, C. (2005). Jóvenes sin tregua: culturas y politicas de la violencia. Barcelona: Anthropos.

Ghiso, A. (2002). Técnicas Interactivas para la Investigación Social Cualitativa. Medellín: Fundación Universitaria Luis Amigó.

Gómez, G. (2012). Estado, barrismo y violencia en el fútbol. En D. Quitian (ed.), Estudios Socioculturales del Deporte. Desarrollos, tránsitos y miradas (pp. 197-214). Armenia: Kinesis.

León, F. (2011). Pobreza, vulnerabilidad y calidad de vida en América Latina: retos para la bioética. Acta Bioethica, 17(1), 19-29. https://doi.org/10.4067/ S1726-569X2011000100003

Montañez, G. y Delgado, O. (1998). Espacio, territorio y región: conceptos básicos para un proyecto nacional. Cuadernos de Geografía, VII(1-2), 120-134.

Panfichi, A., y Thieroldt Llanos, J. (2006). Identidad y rivalidad: clubes de fútbol y barras bravas en el Perú. En A. Meza Salcedo y R. Soto Sulca (eds.), Racionalidad e irracionalidad en la cotidianidad del sujeto. Huancayo: PuntoCom.

Pegorano, J. (2002). Notas sobre jóvenes portadores de la violencia juvenil en el marco de las sociedades pos-industriales. Sociologías, 8, 276-317. https://doi.org/10.1590/ S1517-45222002000200012

Poveda, Clavijo J. (2004). Estudio de barras de fútbol de Bogotá: los Comandos Azules. Universitas Humanistica, XXXI(58), 43-59.

Poveda, Clavijo J. (2010). Cantar bajo la anaconda: un análisis sociocultural del barrismo en el fútbol. Bogotá: Pontificia Universidad Javeriana.

Quitian, D. (2012). Introducción. Del alumbramiento a la pubertad: los estudios sociales del deporte en América Latina en clave colombiana. En D. Quitian (ed.), Estudios socioculturales del deporte. Desarrollos, tránsitos y miradas (pp. 9-20). Armenia: Kinesis.

Raffenstin (1980). Pour une geographie du pouvoir. París: Librairies Techniques.

Reguillo, R. (2012). De las violencias: caligrafía y gramática del horror. Desacatos, (40), 33-46. https://doi.org/10.29340/40.254

Rich, A. (1980). Sobre mentiras, secretos y silencios. Barcelona: Icaria. 
Rivera, O. (2018). Juventudes y barras futboleras en el tránsito de los territorios escolares, locales, digitales y rurales. En Ruralidad y territorio. espacios y actores contemporáneos. Bogotá: Nueva Jurídica.

Salcedo, M. y Rivera, O. (2007). Emoción, control e identidad. Las barras del fútbol en Bogotá. Bogotá: Instituto Colombiano de Antropología e Historia.

Scandroglio, B., Martín, J., Martín, J., López, J., Martín, A., Carmen, M. y Martín, J. (2002). Violencia Grupal juvenil, una revisión crítica. Revista Psicotema, 14, 6-14.

Urbina, J. (2011). Etnografía virtual. En P. Pablo (ed.), La investigación en las ciencias sociales: estrategias de investigación (pp. 169-178). Bogotá: Universidad Piloto de Colombia.

Villanueva, A. (2013). Mi segunda piel: memoria visual de los hinchas del fútbol capitalinos. Bogotá: Fondo Editorial Universidad Pedagógica Nacional de Colombia.

Villanueva, A y Mendivelso, R (2018). Fútbol, barras bravas y convivencia en Colombia. Investigaciones académicas en los últimos quince ańos. Revista digital de la Asociación Latinoamericana de Estudios Sociales del Deporte, 9(3), 727- 851.

Zambaglione, D, (2011). El aguante en el cuerpo. Buenos Aires: Prometeo. 